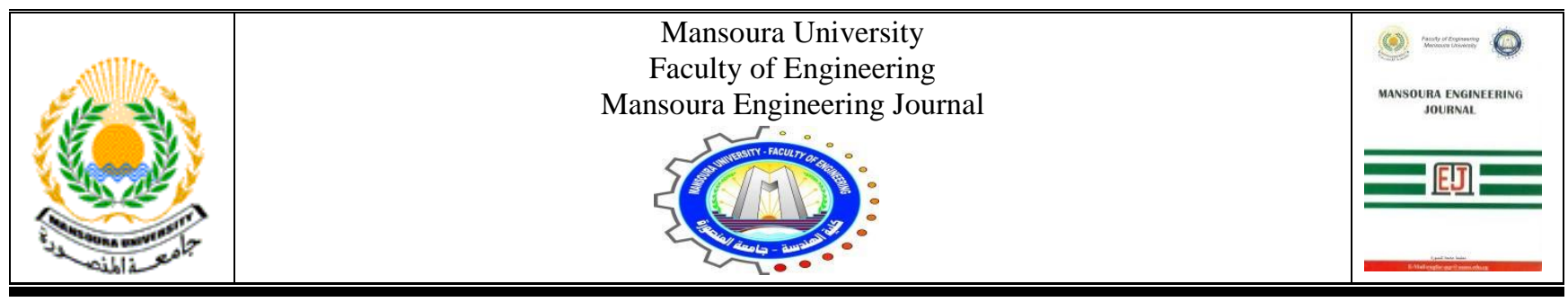

\title{
Locating Multi Types of FACTS for Congestion Management in Deregulated Power Systems Considering Voltage Stability

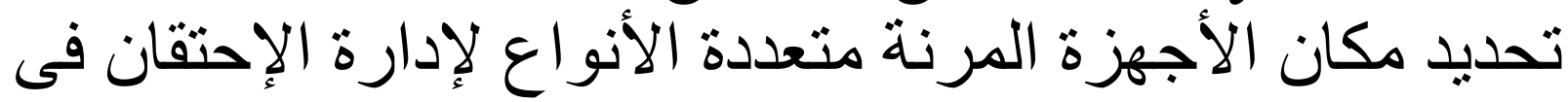

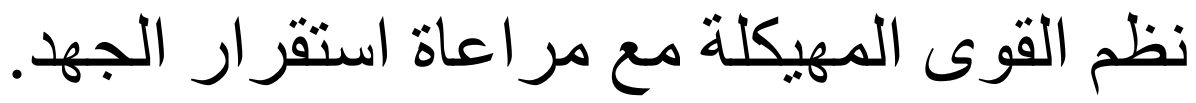

\author{
S. S. Kaddah, A. A. Eladl, and E. A. Haikal
}

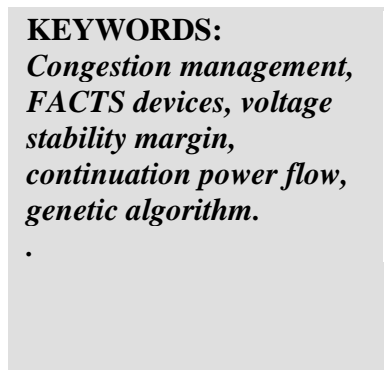

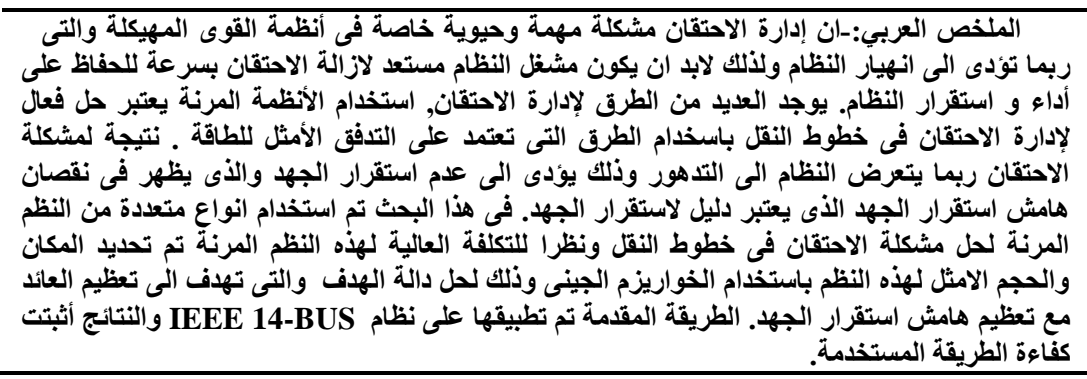

\begin{abstract}
Congestion management is a vital and important problem especially in deregulated power system and may lead to system collapse. So, system operator should be ready to relieve congestion as fast as possible to keep system reliability and stability. There are many methods for congestion management; using Flexible Alternating Current Transmission Systems (FACTS) devices is considered an effective solution for removing congestion in transmission lines employing Optimal Power Flow based methods. Due to congestion problem, the system may be deteriorated and lead to voltage instability and this appears in reducing voltage stability margin (VSM )which is used as an index for voltage stability. In this paper Multi-Types of FACTS devices are used to solve the congestion problem, and because of the high cost of FACTS devices, the optimal locations and sizes is
\end{abstract} 2018

Received: 13 May, 2018 - revised: 19 July, 2018 - accepted: 29 July,

S. S. Kaddah is with the Electrical Engineering Department, Faculty of Engineering, Mansoura University, Mansoura 35516, Egypt (e-mail: skaddah@mans.edu.eg).

Abdelfattah A. Eladl. is with the Electrical Engineering Department, Faculty of Engineering, Mansoura University, Mansoura 35516, Egypt (email: eladle7@mans.edu.eg ).

E. A. Haikal is with the Developing Department, Worker University, Zagazig Branch, Zagazig, Egypt (e-mail: ebtehagali@yahoo.com ). determined by solving the objective function which consists of two parts, maximizing the social welfare (SW), and maximizing the VSM to ensure system stability. The objective function is solved using the Genetic Algorithm (GA). The proposed method is applied on IEEE 14-bus test system and the results confirm the efficiency of the proposed method.

\section{INTRODUCTION}

$\mathrm{D}$ UE to open access strategy in deregulated power market, power flow in transmission lines may exceed or near to its thermal limits and this leads to congestion which causes great problem in transmission network and can cause the power system failure. To solve this problem, there are several methods to alleviate congestion while keeping the power system constraints. FACTS devices are either pure power electronic devices or conventional elements such as resistor, reactor or capacitors controlled by electronic devices. FACTS can increase power transfer capability, control power flow in transmission lines, and also can improve the stability and flexibility of the power network. FACTS devices may be series controller such as Thyristor Controlled Series Capacitors (TCSC), or shunt controllers 
such as Static Var Compensators (SVC), or combined series shunt controllers like Unified Power Flow Controllers (UPFC).

In [1] a simple and efficient method is presented for optimal location of FACTS devices for congestion management, the method is based on real power flow performance index (PI) and the best choice of FACTS location is based on the reduction of congestion cost. In [2] UPFC is used for congestion management, the suitable location of UPFC is decided based on PI sensitivity of control parameters of UPFC and its objective is reducing real power losses and real power flow. Multi-Objective genetic algorithm technique is used to determine the optimal choice and allocation of FACTS controllers in deregulated power system in [3] and the objective is maximization of branch loading, voltage stability and minimization of losses independently. In [4] series FACTS are used for congestion management based on reduction of total system VAR losses and performance index.

In [5] genetic algorithm is used for optimal location of different types of FACTS devices such as TCSC and UPFC for relieving congestion and social welfare maximization. In [6] FACTS devices and load shedding are used for transmission line overload alleviation by Extended Quadratic Interior Point (EQIP) based OPF. Optimal placement of UPFC is detected to voltage drop compensation and reduces congestion in [7], the optimal location is determined using voltage drop index (VDI) and congestion rent contribution factor. In [8,9] TCSC is used for congestion management and the best location for TCSC placement is determined based on reactive power loss sensitivity factor. In [10] the best location of TCSC is determined for congestion removing used priority list to have minimum total congestion rent and minimum total generation cost.

In [11] UPFC and STATCOM are used for reducing congestion by controlling the power flow in transmission lines especially heavy loaded lines. A simple test system is simulated and analyzed with and without these FACTS devices to study the steady state operation of the system and the effect of their performance is observed.

Congestion is managed by re-dispatching of active power and application of FACTS in [12]. The re-dispatching is an optimization problem solved based on two objectives, minimum cost of congestion that payed by ISO and minimum value of dispatch power of generators. TCSC and TCPAR are used to relieve congestion and reduce the amount of redispatched power and congestion cost. The effect of FACTS devices is observed when applied on 14-bus test system and the results are satisfied. In [13] series FACTS devices as TCSC is used reduce congestion in deregulated electricity market locational marginal price (LMP) difference and congestion rent are used to form the priority list on which the optimal location of TCSC is determined. The proposed method is applied on 14-bus, 30-bus and 57-bus test systems based on the main objective which is maximize the social welfare or minimize the congestion rent. In [14] TCSC is used for the purpose of maximization of social welfare in deregulated power system, the proposed method was used to evaluate the benefit of TCSC in increasing the generator and load surplus and convert these benefits to monetary values. In
[15] SVC and TCSC are installed into the electric power system to reduce congestion considering voltage stability. The objective was minimization of the annual device investment cost and maximizing the annual benefit which is defined as the difference between the security cost with and without FACTS devices.

Multi-Objective genetic algorithm optimization technique is used in [16] as a tool for determining the optimal location of FACTS devices to reduce congestion in deregulated electricity market considering branch loading, voltage stability and loss minimization. These three objectives were satisfied using TCSC and SVC. In [17] general review on congestion management in electric power systems. In [18] multi-objective particle swarm optimization technique is used to locate TCSC in optimal location base on the objective of minimizing the total generation cost and minimizing the installation cost of TCSC. SQP is used to solve this problem and the collapse point is applied to calculate the margin of load during contingency. This method is applied on 14-bus test system and the results were satisfied. Multi-types of FACTS devices are placed into 5-bus test system in [19] to maximize social welfare and minimize the total operating cost. Evolutionary programing (EP) and differential evolution techniques were used for this purpose. The proposed method also reduced the total number of overloaded lines.

In this paper the effect of using FACTS devices for congestion management in deregulated environment is studied. Optimal size and location of TCSC and SVC are determined using genetic algorithm optimization technique. The objective function is divided into two parts: maximizing the social welfare and maximizing the voltage stability margin. The rest of the paper is organized as following: section 2 presents modeling of FACTS devices, TCSC and SVC. Section 3 discusses congestion management using FACTS devices. Voltage stability definition, classification and voltage stability margin are presented in section 4 . In section 5 genetic algorithm is presented as an optimization technique. Problem formulation is presented in section 6. Simulation and results are discussed in section 7 . Finally, conclusion of the paper is presented in section 8 .

\section{MOdeling OF FACTS DEVICES}

Facts are integrated concepts based on power electronic switching converters used to improve the performance of the power system as power transfer capability, stability, reliability and security of the power system.

FACTS can be modeled as power injection model (PIM) or impedance insertion model (IIM), in power injection model FACTS devices are modelled as a device injects active or reactive power to the node at which it is connected, but in impedance insertion model FACTS devices are inserted to the system as known impedance connected to the system in series, shunt or combination according to the type of the device. In this paper two types named SVC and TCSC are chosen because of their low cost and the ability to increase loadability $[13,14]$. 


\section{A.Modeling of Thyristor Controlled Series Compensator (TCSC)}

Many models can be used for modelling TCSC as series FACTS devices, it depends on the study and application for which it is used. TCSC is presented as a variable static capacitor between buses $\mathrm{i}$ and $\mathrm{j}$ as shown in Fig. 1 The model consists of fixed capacitor in parallel with a thyristorcontrolled reactor. Locating TCSC through transmission line change the total reactance of the T.L. either the TCSC is capacitive or inductive element. For static application FACTS devices, can be modelled as a power injection model injects active or reactive power to a node. So, FACTS devices are presented as PQ elements [27].

TCSC in the power injection model is represented by four injected power as follows: [20]

$$
\begin{gathered}
P_{i}^{T C S C}=\left|V_{i}\right|^{2} \Delta G_{i j}-\left|V_{i}\right|\left|V_{j}\right|\left[\begin{array}{c}
\Delta G_{i j} \cos \left(\delta_{i}-\delta_{j}\right) \\
+\Delta B_{i j} \sin \left(\delta_{i}-\delta_{j}\right)
\end{array}\right] \\
Q_{i}^{T C S C}=-\left|V_{i}\right|^{2} \Delta B_{i j}-\left|V_{i}\right|\left|V_{j}\right|\left[\begin{array}{c}
\Delta G_{i j} \sin \left(\delta_{i}-\delta_{j}\right) \\
-\Delta B_{i j} \cos \left(\delta_{i}-\delta_{j}\right)
\end{array}\right] \\
P_{j}^{T C S C}=\left|V_{j}\right|^{2} \Delta G_{i j}-\left|V_{i}\right|\left|V_{j}\right|\left[\begin{array}{c}
\Delta G_{i j} \cos \left(\delta_{i}-\delta_{j}\right) \\
-\Delta B_{i j} \sin \left(\delta_{i}-\delta_{j}\right)
\end{array}\right] \\
Q_{j}^{T C S C}=-\left|V_{j}\right|^{2} \Delta B_{i j}+\left|V_{i}\right|\left|V_{j}\right|\left[\begin{array}{c}
\Delta G_{i j} \sin \left(\delta_{i}-\delta_{j}\right) \\
+\Delta B_{i j} \cos \left(\delta_{i}-\delta_{j}\right)
\end{array}\right]
\end{gathered}
$$

Where $P_{i}^{T C S C}, Q_{i}^{T C S C}, P_{j}^{T C S C}, Q_{j}^{T C S C}$ are power injections due to installing TCSC in branch $\mathrm{i}-\mathrm{j}$. Also, $\left|V_{i}\right|, \delta_{i},\left|V_{j}\right|, \delta_{j}$ are voltage magnitudes and phases of buses $\mathrm{i}$ and $\mathrm{j} . \Delta G_{i j}, \Delta B_{i j}$ depend on TCSC reactance are given as:

$$
\begin{gathered}
\Delta G_{i j}=\frac{x_{c} r_{i j}\left(x_{c}-2 x_{i j}\right)}{\left(r_{i j}^{2}+x_{i j}^{2}\right)\left\{r_{i j}^{2}+\left(x_{i j}-r_{i j}\right)^{2}\right\}} \\
\Delta B_{i j}=-\frac{\mathrm{x}_{\mathrm{c}}\left(\mathrm{r}_{\mathrm{ij}}^{2}-\mathrm{x}_{\mathrm{ij}}^{2}+\mathrm{x}_{\mathrm{c}} \mathrm{x}_{\mathrm{ij}}\right)}{\left(\mathrm{r}_{\mathrm{ij}}^{2}+\mathrm{x}_{\mathrm{ij}}^{2}\right)\left\{\mathrm{r}_{\mathrm{ij}}^{2}+\left(\mathrm{x}_{\mathrm{ij}}-\mathrm{r}_{\mathrm{ij}}\right)^{2}\right\}}
\end{gathered}
$$

where $r_{i j}$ and $x_{i j}$ are resistance and reactance of the transmission line at which the TCSC is located. The setting of TCSC should be within limits between $-0.7 \mathrm{X}_{\mathrm{L}}$ inductive and $0.2 \mathrm{X}_{\mathrm{L}}$ capacitive where $\mathrm{X}_{\mathrm{L}}$ is the reactance of the line.

$$
-0.7 X_{L}<X_{T C S C}<0.2 X_{L}
$$

The total reactance of the transmission line after installing TCSC is given by: [20]

$$
X_{i j}=X_{\text {Line }}+X_{T C S C}
$$

where $X_{i j}$ is the new reactance of the transmission line between buses $\mathrm{i}$ and $\mathrm{j}$ after installing TCSC, $\mathrm{X}_{\text {Line }}$ is the reactance of the transmission line and $\mathrm{X}_{\mathrm{TCSC}}$ is the reactance contributed by the TCSC.

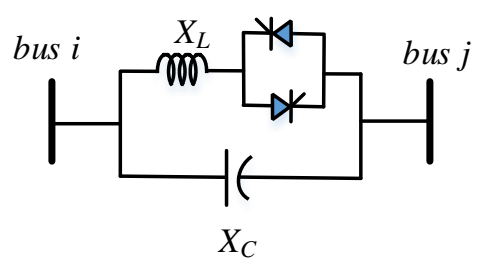

(a)

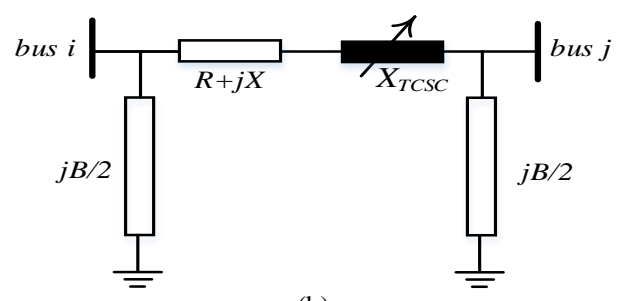

(b)

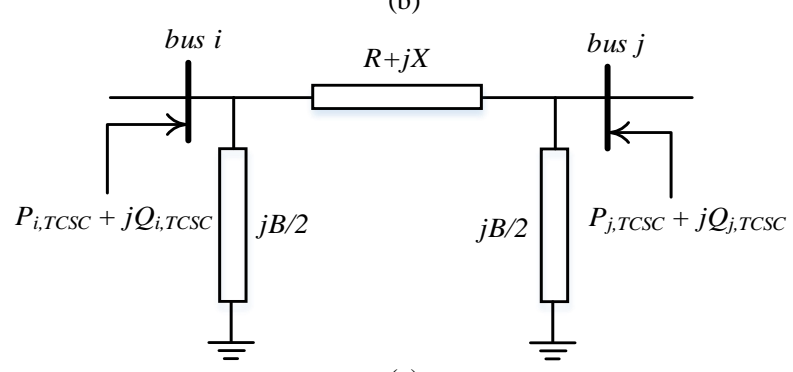

(c)

Fig. 1. Thyristor series compensator TCSC.

(a) basic structure (b) steady-state model (c) power injection model

\section{B. Modelling of Static Var Compensator (SVC)}

SVC is a shunt connected static var generator or absorber whose output is adjusted to control parameters of the power system by changing capacitive or inductive current. SVC is consisted of TCR (thyristor controlled reactor) or TSC (thyristor switched capacitor) in parallel with fixed capacitor as shown in Fig. 2 SVC is modelled to inject or absorb reactive power at the bus where it is connected and this is according to the state of the system i.e. if the system has an increase in reactive power the SVC becomes inductive and absorbs reactive power from the system and if the load becomes more inductive the SVC becomes capacitive and injects reactive power to the system. The reactive power limits for SVC placed in buses are as following: [21]

$$
\begin{gathered}
Q_{s v c}=-V_{i}^{2} \times B_{s v c} \\
-200 M V A r \leq Q_{s v c} \leq 200 M V A r
\end{gathered}
$$

where $Q_{s v c}$ is the capacity of SVC in MVAr, $\mathrm{V}_{\mathrm{i}}$ is the voltage at the bus at which $\mathrm{SVC}$ is connected and $B_{s v c}$ is the susceptance of SVC. 


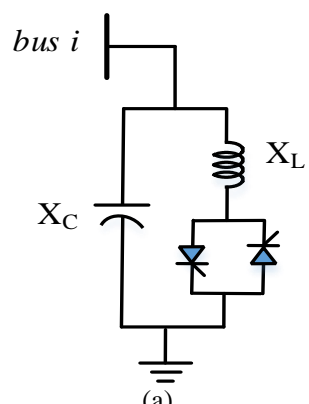

Fig. 2. Static var compensator.

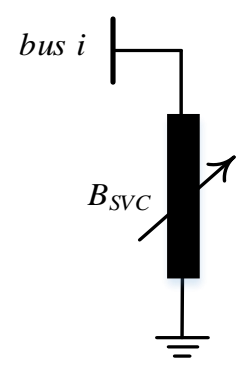

(b) (a) basic structure

(b) steady-state mode

\section{Congestion manAgEMENT USING FACTS}

Congestion management (CM) in deregulated electricity power market is very important and vital problem, it may occur due to sudden increase in load demand, lack of coordination between generation and transmission utilities, or any contingency such as outage of a transmission line or generator, or any failure of any equipment in the electric power system. Congestion in the electric power system may lead to many problems as increasing the price of the electric energy (LMP), increasing system losses, cascading outage of the transmission lines and may lead to system failure or collapse. So, ISO should take action when congestion occurred to maintain the stability of the power system taking into consideration the operating cost for solving the problem. There are lots of methods to solve the congestion problem such as building new generating units near the load centers, building new transmission lines in appropriate locations, generation rescheduling of real power output, reduction of load demand using load shedding program [22]. One widely used method for congestion management is installing of FACTS devices, and because of the high cost of FACTS, an optimization technique is used to determine optimal size and location for it.

\section{LOCATIONAL MARGINAL PRICING (LMP)}

LMP is a market-pricing approach used to manage the use of transmission system in a sufficient way when congestion occurs on the bulk power grid. LMP is defined as the marginal cost of supplying, at least cost, the next increment of active power demand at a specific node on the electric power network taking into account generation companies offers, loads bids and physical aspects of the system without violating any system security limit. LMP can also defined as nodal pricing or spot price and it is the same at all nodes of the system when the system is unconstrained and lossless [23]. If the transmission losses are neglected and the system is constrained, LMP differs from location to another due to congestion which results an increase in nodal pricing and prevents low cost generators from meeting loads. So more expensive electricity from high cost generators is needed to meet that demand. For this reason, CM becomes very important and necessary [24].

The locational marginal pricing at any location is the sum of three components; the first one is the marginal energy component, which is the same for all buses. The second is congestion component and the third is marginal losses component [20]. LMP can be derived directly from AC-OPF or DC-OPF but the first is more accurate.

Power suppliers (generators) provide offers to sell energy and consumer (load serving entities) provide bids to purchase energy, according to these offers, bids and system operating conditions LMP is determined [25].

\section{VOLTAGE STABILITY}

\section{A. Definition and classification}

Voltage stability (VS) becomes very serious problem in electric power system planning and operation. Voltage stability is concerned with the ability of the power system to maintain voltage values at allowable limits at normal operation and also after the system is subjected to a disturbance [27]. Voltage stability can be classified into shortterm and long-term voltage stability. The short-term VS involves fast acting of load component such as induction motors or electronically controller loads and the study period is several seconds. While long- term VS involves slow acting equipment like tap changing transformer or generator current limiters and the study period is several minutes.

The system is being unstable if voltage at one bus or more hits the acceptable range, voltage instability may or may not lead to voltage collapse according to the reaction of ISO who uses voltage stability index to study how close the system to voltage collapse point. There are many indices for VS studies; one of these is VSM which is mostly used for this purpose.

\section{B. Voltage stability margin (VSM)}

VSM is defined as the distance between the current operating point and the voltage collapse point. It is used as an index for determining the voltage stability of the power system. To study the voltage stability, Continuation Power Flow (CPF) is used as a tool for voltage stability bifurcation analysis.

In CPF, loads and generations are increased by loading parameter $\lambda$ as [26]:

$$
\begin{aligned}
& P_{d}=P_{d(\text { base case })}+\lambda P_{d_{-} \text {step }} \\
& Q_{d}=Q_{d(\text { base case })}+\lambda Q_{d_{-} \text {step }} \\
& P_{g}=P_{g(\text { base case })}+\left(\lambda+k_{g}\right) \cdot P_{g_{\text {step }}}
\end{aligned}
$$

where $P_{d(\text { base case) }}, Q_{d(\text { base case) }}, P_{g(\text { base case) }}$ are powers of loads and generators at the base case and $\mathrm{P}_{\mathbf{d} \_ \text {step }}, \mathrm{Q}_{\mathbf{d}_{\text {_step }}}, \mathrm{P}_{\mathbf{g}_{\text {_step }}}$ are load and generator power increments. $K_{g}$ is a parameter balances the system losses when load and generation are increased.

Then VSM can be considered as a function of the decision variables of the congestion management problem.

$$
V S M=f\left(P_{d} \cdot Q_{d} \cdot P_{g}\right)
$$




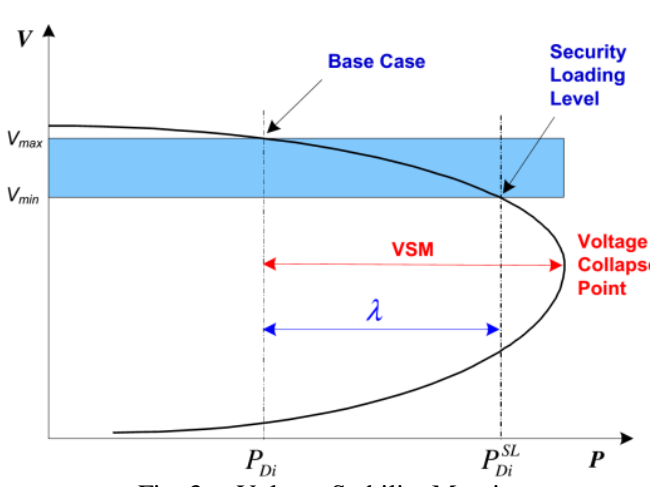

Fig. 3. Voltage Stability Margin

\section{GENETIC ALGORITHM (GA)}

Genetic algorithms are search methods based on principles of natural selection and genetics. GA is used as an optimization technique which evaluate the target function to be minimized or maximized according to the fitness function. At first the objective problem is encoded into chromosomal manner and fitness function is determined then GA starts steps of solution which are: [28, 29]

Initialization: the initial population candidate solutions are selected randomly from the search space.

Evaluation: after determining the population, the fitness function is evaluated to determine the populations with highest fitness value.

Selection: in this step the better solution with highest fitness values are selected.

Recombination: two or more solutions are combined to create a new possible better solution

Mutation: mutation performs a random change to the candidate solutions.

Replacement: the offspring solutions selected, recombined and mutated replaces the original solutions. GA gives good results compared with other optimization methods

\section{Problem Formulation}

This part presents the mathematical formulation of the proposed objective function which is divided into two parts; the first one is the main objective $\left(\mathrm{F}_{1}\right)$ that aims to maximize the social welfare. The second part is $\left(\mathrm{F}_{2}\right)$ that aims to maximize VSM after CM is relieved to keep the stability of the system.

The flowchart of the proposed algorithm is shown in Fig. 4.

The Objective Function.

1. Maximizing the social welfare.

$$
F_{1}=\sum_{i \in S D}^{N_{D}} B_{D i}\left(P_{D i}\right)-\sum_{i \in S G}^{N_{G}} C_{G i}\left(P_{G i}\right)-F A C T S_{c o s t}
$$

where $\mathrm{N}_{\mathrm{G}}$ is the number of generators, $\mathrm{N}_{\mathrm{D}}$ is the number of loads, $\mathrm{C}_{\mathrm{Gi}}\left(\mathrm{P}_{\mathrm{G}}\right)$ is the bid offers of the $\mathrm{i}^{\text {th }}$ generator and $\mathrm{B}_{\mathrm{Di}}\left(\mathrm{P}_{\mathrm{D}}\right)$ is the benefit of the $i^{\text {th }}$ demand.

$$
\begin{aligned}
B_{D i}\left(P_{D}\right) & =\sum_{i=1}^{N_{d}} P D_{i} \lambda_{i} \\
C_{G i}\left(P_{G}\right) & =\sum_{i=1}^{N_{g}} P g_{i} \lambda_{i}
\end{aligned}
$$

where $N_{d}$ is the total number of load buses, $P D_{i}$ is the real power of load demand at bus $i$ (MW), $N_{g}$ is the total number of generators buses, $P g_{i}$ is active power generated at bus $i$ (MW) and $\lambda_{i}$ is the locational marginal price at $i^{\text {th }}$ bus $(\$ / M W)$ which is obtained from OPF.

$$
\begin{aligned}
& \text { FACTS }_{\text {cost }}=\sum_{i \in I} S_{T C S C . i} \cdot C_{T C S C}+\sum_{j \in J} S_{S V C . j} \cdot C_{S V C} \\
& C_{T C S C}=0 \cdot 0015 S_{T C S C}^{2}-0 \cdot 713 S_{T C S C}+153 \cdot 75 \\
& C_{S V C}=0 \cdot 0003 S_{S V C}^{2}-0 \cdot 3051 S_{S V C}+127 \cdot 38
\end{aligned}
$$

where $S_{\mathbf{T C S C}}$ and $\mathrm{S}_{\mathbf{S V C}}$ are the reactive power injection due to installing of TCSC and SVC respectively [22,30,31].

\section{2- Maximize the voltage stability index}

$$
F 2=V S M_{0}+\Delta V S M
$$

where $\mathrm{VSM}_{0}$ is the base case voltage stability margin and $\triangle \mathrm{VSM}$ is the change in it after congestion management and can be expressed as following: [32]

$$
\begin{aligned}
\Delta V S M= & -\frac{\partial V S M}{\partial Q_{d i}^{T C S C}} \cdot Q_{i}^{T C S C}-\frac{\partial V S M}{\partial Q_{d j}^{T C S C}} \cdot Q_{j}^{T C S C} \\
& +\sum_{K \in S D} \frac{\partial V S M}{\partial Q_{D K}} \cdot \Delta Q_{D K}
\end{aligned}
$$

where $i$ and $j$ are the two terminal buses of the branch where the TCSC is installed, $Q_{i}^{T C S C}$ and $Q_{j}^{T C S C}$ are the reactive power injected at buses $\mathrm{i}$ and $\mathrm{j}$ due to installing TCSC. In fact, the effect of active power on voltage stability margin is little so, the effect of active power injected by TCSC is ignored. And the final VSM after congestion management is given in equation F2 [25]. 
The total objective function is the summation of the above two objectives:

$$
F=F 1+\omega . F 2
$$

Where $\omega$ is weighting factor determined according to the operating condition of the system.

\section{Constraints.}

The objective function is subjected to equality and inequality constraints as following:

\section{Equality constraints}

- system power balance

-

$$
\sum_{i=1}^{N_{g}} P_{g i}-\sum_{i=1}^{N_{d}} P_{D i}-P L=0
$$

\section{Inequality constraints}

- Generator capacity constraints,

$$
\begin{aligned}
& P g_{i}^{\text {min }} \leq P g_{i} \leq P g_{i}^{\text {max }} \\
& Q g_{i}^{\text {min }} \leq Q g_{i} \leq Q g_{i}^{\text {max }}
\end{aligned}
$$

where

$P g_{i}^{\text {min }}$ is the minimum value of the active power output from the $i^{\text {th }}$ generator,

$P g_{i}^{\max }$ is the maximum value of the active power output from the $i^{\text {th }}$ generator,

$Q g_{i}^{\text {min }}$ is the minimum value of the reactive power output from the $i^{\text {th }}$ generator, and

$Q g_{i}^{\max }$ is the maximum value of the reactive power output from the $i^{\text {th }}$ generator.

\section{- Voltage constraints:}

The bus voltage level should be within maximum and minimum limits which is expressed as:

$$
V_{i}^{\min } \leq V_{i} \leq V_{i}^{\max }
$$

where $V_{i}^{\text {min }}$ is the lower bound of voltage magnitude at the $i^{\text {th }}$ bus, and $V_{i}^{\max }$ is the upper bound of voltage magnitude at the $i^{\text {th }}$ bus.

\section{- Security constraint:}

The transmission line loading factor must be within limits for safety

$$
0 \leq\left|L_{i j}\right| \leq 1 \quad, \quad L_{i j}=\frac{S_{i j}}{S_{i j}^{\max }}
$$

where $S_{i j}$ is the power flow in line between bus $\mathrm{i}$ and bus $\mathrm{j}$ and $S_{i j}^{\max }$ is the maximum limit of power flow on line between bus $\mathrm{i}$ and bus $\mathrm{j}$ in MVA.

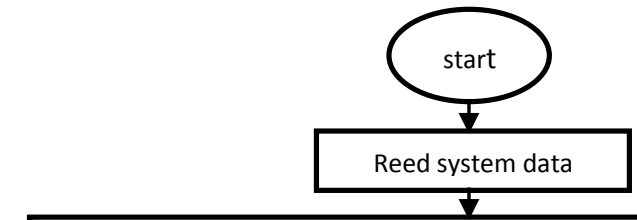

Increasing load at all buses of the system until the system congested.

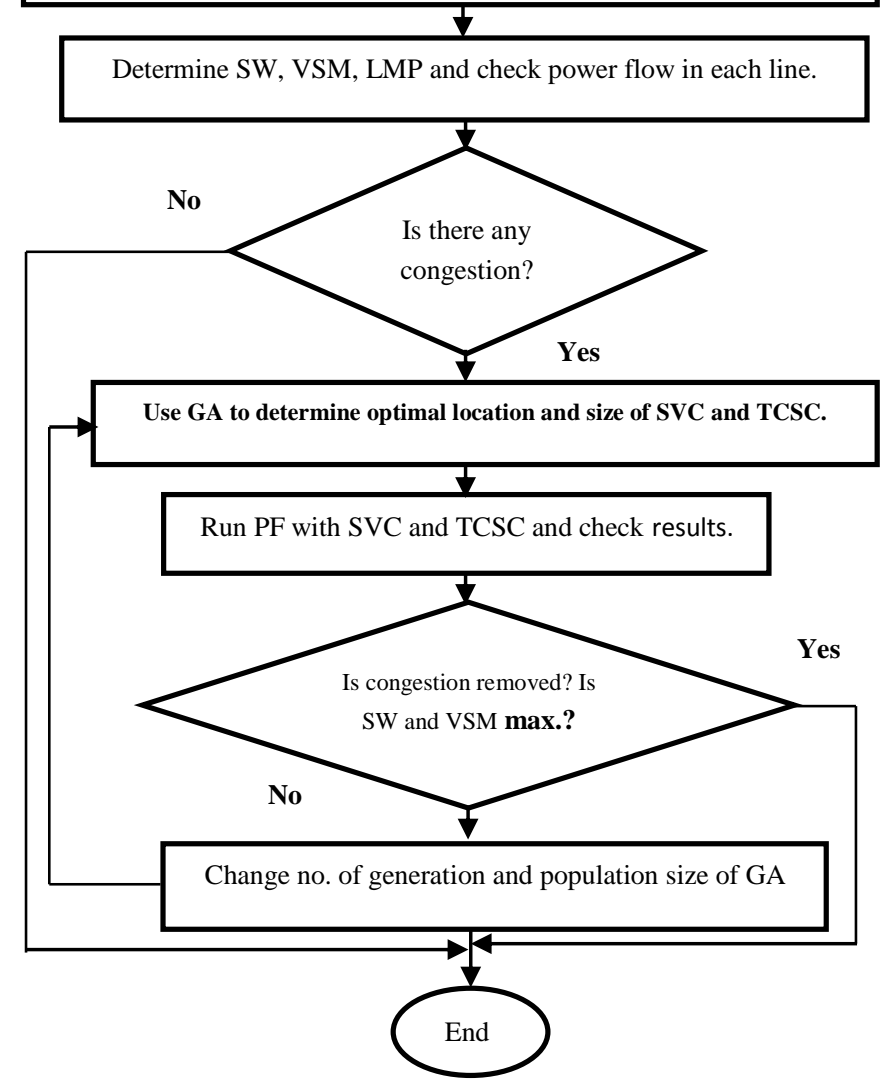

Fig. 4. Flowchart for the proposed algorithm.

\section{SIMUlation AND RESUltS}

The proposed method is applied on IEEE 14-bus test system, the system is consisted of 14 buses, 20 transmission lines, 5 generators, the detailed data for generators, loads and limits of transmission lines are given in [33]. Loads are divided into three load groups, load group 1 includes loads at buses 5, 10, 12. Load group 2 includes loads at buses 4, 11, 13. Loads at buses 9, 14 are included in load group 3. Loads in each group are increased with different percentage along all hours of the day, and the performance of the system is studied at each hour, the system daily load curve is shown in fig. 5 which shows the variation of load in each group at each hour of the day.

When the system is congested due to load variation along the day, lines (9-7) and (10-11) are overloaded at certain hours, line (9-7) is more overloaded from the $8^{\text {th }}$ hour to the end of the day and line (10-11) is overloaded at all hours of the day, and then the system is congested, FACTS devices are installed into the system to remove congestion and improve system performance. Optimal size and locations of FACTS devices (FD) are determined using genetic algorithm, four 
TCSC and two SVC are installed into the system, their optimal sizes and locations are presented in Table I, which shows that the optimal locations of SVC are at buses 4, 5 with optimal sizes 184.37 Mvar, 50.25 Mvar, respectively. With respect to TCSC, the optimal locations are lines 7, 16, 5, 4 with optimal capacities 0.1884 Mvar, 0.0008 Mvar, 2.047 Mvar, 1.224 Mvar, respectively.

TABLE 1

OPTIMAL SIZES AND LOCATIONS OF FD IN NORMAL CASE FOR IEEE 14 BUS

\begin{tabular}{c|c|c|c}
\multicolumn{2}{c}{ FACTS Type } & $\begin{array}{c}\text { Location } \\
\text { (Bus / Line) }\end{array}$ & $\begin{array}{c}\text { Size } \\
\text { (Mvar) }\end{array}$ \\
\hline \multirow{2}{*}{$\begin{array}{c}\text { Shunt } \\
\text { Type }\end{array}$} & SVC1 & 4 & 184.37 \\
\cline { 2 - 4 } Series \\
Type & SVC2 & 5 & 50.25 \\
\cline { 2 - 4 } & TCSC1 & $7(4-5)$ & 0.1884 \\
\cline { 2 - 4 } & TCSC2 & $16(9-10)$ & 0.0008 \\
\cline { 2 - 4 } & TCSC3 & $5(2-5)$ & 2.047 \\
\cline { 2 - 4 } & TCSC4 & $4(2-4)$ & 1.224
\end{tabular}

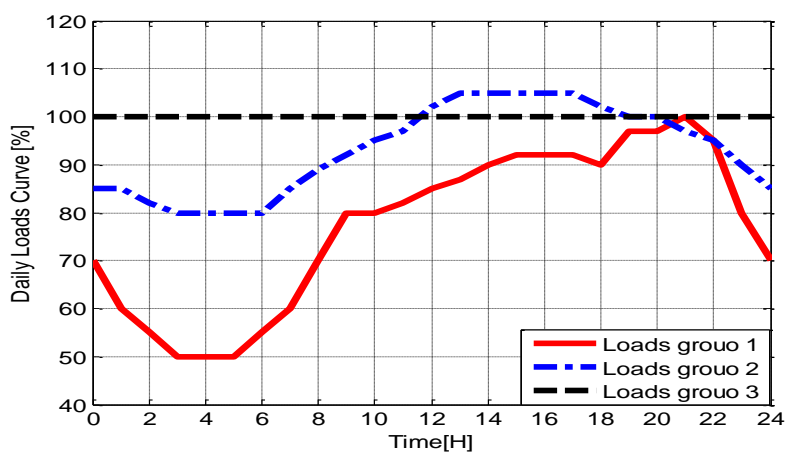

Fig. 5. Daily load curve

Adding FD to the power system remove congestion in the overloaded lines and then the power flow in lines (9-7) and (10-11) become within acceptable limits, the power flow in these lines before and after inserting FD are shown in figures 6,7 respectively. For line (9-7), the effect of FD is clear at the first hours of the day then their effect is reduced from $14^{\text {th }}$ hour to $22^{\text {th }}$ hour and at the end of the day the effect of FD appears again. Generally, the effect of FD is clear in removing congestion in line (9-7).

In figure 7, FD relieves congestion in line (10-11) but it is clear more at the middle of the day from $7^{\text {th }}$ hour to $20^{\text {th }}$ hour.

Due to installing of FD into the system, the social welfare (SW) is increased as the power system loadability and power losses are much improved. The results are presented in Table II. which shows that the SW at each hour of the day is increased with high degree except from hour $19^{\text {th }}$ to $22^{\text {th }}$ the effect of FD is not highly clear.

The effect of FD on SW is clear especially in the first half of the day, the SW is maximized with high degree. Variation of SW during 24 hours is shown in fig. 8.

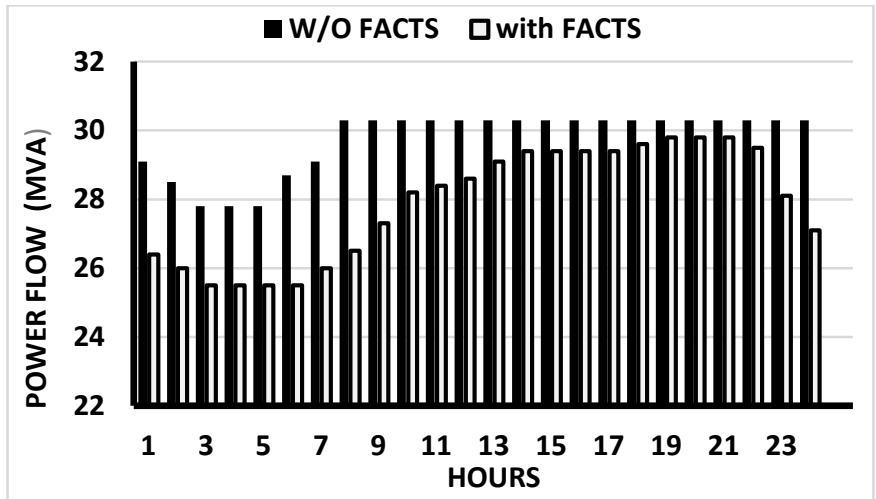

Fig. 6. Power flow in line $(9-7)$ with and without FD.

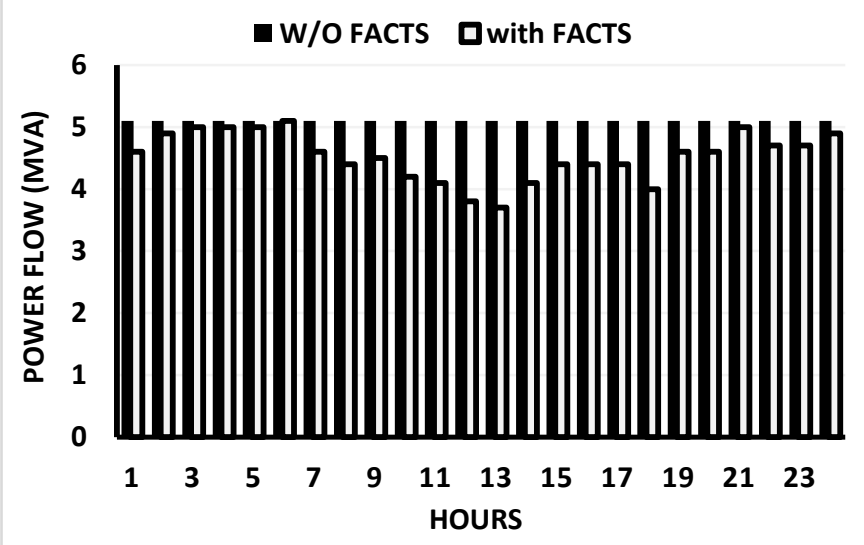

Fig. 7. power flow in line $(10-11)$ with and without FACTS

Also, adding of FD affects the voltage stability of the power system by increasing VSM\% as a percentage of its value at the base case, the relation between VSM\% with and without FACTS devices during 24 hours is shown in fig. 9, and it is clear that VSM\% is increased after inserting FD into the system and removing congestion.

TABLE 2

SOCIAL WELFARE AT EACH HOUR FOR IEEE 14 BUS SYSTEM

\begin{tabular}{c||c||c||c||c||c}
\multicolumn{1}{c||}{ Hours } & \multicolumn{2}{c}{ Social welfare } & \multicolumn{1}{c}{ Social welfare } \\
& $\begin{array}{c}\text { W/O } \\
\text { FACTS }\end{array}$ & $\begin{array}{c}\text { With } \\
\text { FACTS }\end{array}$ & \multicolumn{1}{c}{ Hours } & $\begin{array}{c}\text { W/O } \\
\text { FACTS }\end{array}$ & $\begin{array}{c}\text { With } \\
\text { FACTS }\end{array}$ \\
\hline 1 & 4015.2 & 16024.7 & 13 & 11686 & 15442 \\
\hline 2 & 3972.2 & 14841.7 & 14 & 11038 & 15399 \\
\hline 3 & 3938.7 & 13855.9 & 15 & 12582 & 12733 \\
\hline 4 & 3938.7 & 13855.9 & 16 & 12582 & 12733 \\
\hline 5 & 3938.7 & 13855.9 & 17 & 12582 & 12733 \\
\hline 6 & 3948.6 & 14508.5 & 18 & 11799 & 15619 \\
\hline 7 & 4015.2 & 16024.7 & 19 & 12175 & 12218 \\
\hline 8 & 4174.9 & 18330.3 & 20 & 12175 & 12218 \\
\hline 9 & 5146.1 & 22203.6 & 21 & 10741 & 11057 \\
\hline 10 & 5136.5 & 22870.5 & 22 & 9502 & 9690.2 \\
\hline 11 & 7704.2 & 26080.9 & 23 & 5101.5 & 21680.4 \\
\hline 12 & 9591.9 & 21759.5 & 24 & 4161.5 & 17594.5
\end{tabular}




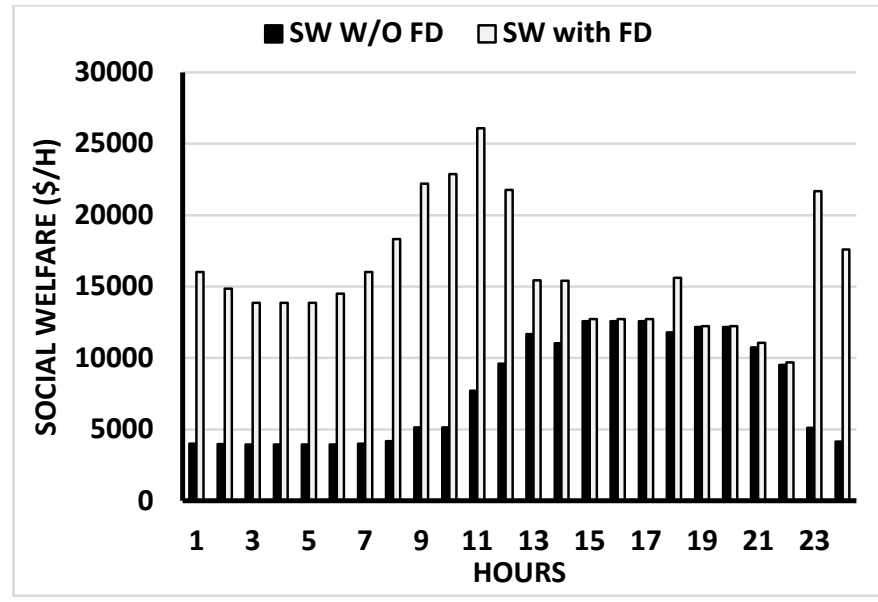

Fig. 8. Social welfare variation along the day

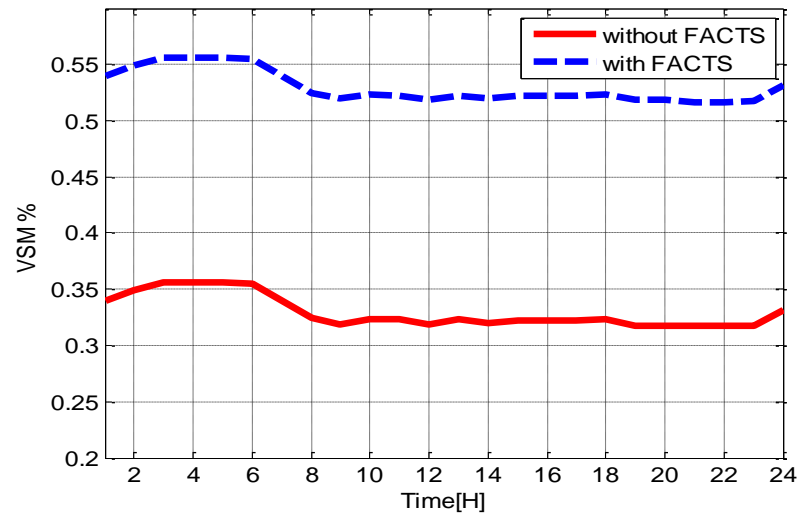

Fig. 9. VSM\% with and without FACTS

Since the system by FD, the bus voltage is improved and kept within acceptable limits which are 0.95 p.u minimum and 1.1 p.u maximum at all buses of the system along all hours of the day even with high loading of the system, the minimum bus voltage at all buses with and without FD is shown in fig. 10 and it is shown that the voltage at all buses is within limits.

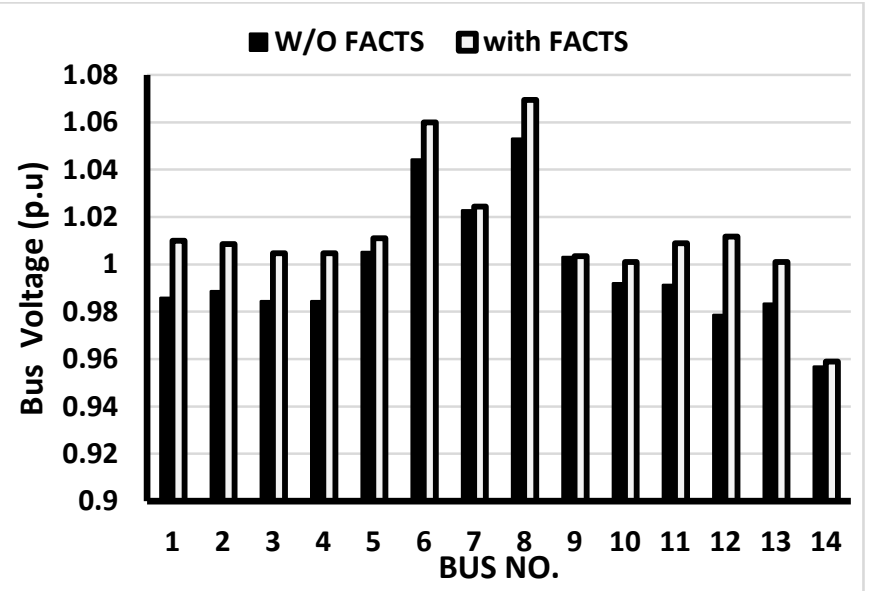

Fig. 10. Minimum bus voltage all buses of 14-bus system.

It is clear that FD has great effect on power system performance either in removing congestion, keeping voltage stability, maximizing VSM, and maximizing SW. Total social welfare with and without FD, net increase in SW due to installing FD and maximum value of VSM\% with and without
FD are presented in Table III. The social welfare increased from 185645.9 \$/day without FD to 371161.4 \$/day with FD and the maximum value of maximum VSM change from $35.6 \%$ without FD to $53.4 \%$ with FD. (All these values are along all hours of the day).

TABLE 3

TOTAL SOCIAL WELFARE AND FD COST FOR IEEE 14 BUS SYSTEM

\begin{tabular}{c|c} 
Item & Amount \\
\hline Total social welfare without FD (\$/day) & 185645.9 \\
\hline Total social welfare with FD (\$/day) & 371161.4 \\
\hline $\begin{array}{c}\text { Increase in social welfare due to FD } \\
\text { (\$/day) }\end{array}$ & 185515.5 \\
\hline Maximum VSM\% without FD & 35.6 \\
\hline Maximum VSM\% with FD & 53.4
\end{tabular}

\section{CONCLUSION}

In this paper, FACTS devices are used as an effective method for congestion management. SVC and TCSC are modeled and analyzed in this paper. Because of high cost of FACTS devices, their optimal sizes and locations are determined using genetic algorithm as an optimization tool in order to satisfy the objective function which is maximizing social welfare and maximizing voltage stability margin. The presented algorithm is applied on IEEE 14 bus system which is congested due to increasing load at all load buses which are divided into three groups. Two SVCs and four TCSCs are inserted into the system and the congestion is removed and the objective function is satisfied by maximizing the social welfare and voltage stability margin the overloading in lines (9-7) and (10-11) is removed and the social welfare is increased from $185645.9 \$$ without FD to $371161.4 \$$ with FD and the VSM\% is increased from 0.5562 without FD to 0.9769 with FD, generally, the results was satisfied.

\section{REFERENCES}

[1] S. N. Singh, A. K. David, "Optimal location of FACTS devices for congestion management”, Electric Power System Research, Vol. 58, PP 71-79, 2001.

[2] K. S. Verma, S. N. Singh and H. O. Gupta, "Location of unified power flow controller for congestion management", Electric Power System Research, Vol. 58, PP 89-96, 2001.

[3] S. S. Reddy, M. S. Kumari and M. Sydulu, "Congestion Management in Deregulated Power System by Optimal Choice and Allocation of FACTS Controllers Using Multi-Objective Genetic Algorithm", International Journal of Electrical Engineering \& Technology, Vol. 4, No. 4, PP 467475, 2009.

[4] L. Rajalakshmi, M. Suganyadevi and S. Parameswari, "Congestion Management in Deregulated Power System by Locating Series FACTS Devices", International Journal of Computer Applications, Vol. 13, No. 8, January 2011.

[5] K. Vijaykumar, "Optimal Location of FACTS Devices for Congestion Management in Deregulated Power System", International Journal of Computer Application, Vol.16, No.6, February 2011.

[6] Elango.K, Paranjothi.S.R, "Congestion management in restructured power systems by FACTS devices and load shedding using extended Quadratic interior point method", International Journal of Applied Engineering research, Vol.1, No.4, 2011.

[7] Saber Izadpanah, Somayeh Hasanpour, "Voltage Drop Compensation and Congestion Management by Optimal Placement of UPFC", International Journal Automation and Power Engineering, 2012, May 2012.

[8] G. Ramesh, T.K. Sunil, "Congestion Management in a Deregulated Power System with Thyristor Controlled Series Capacitor", International Journal of Engineering Research and technology, Vol. 2, No. 11, Nov. 2013. 
[9] G. Vinod, J. Srinivasa, J. Amarnath, "Transmission Congestion Management by Using Series FACTS Devices and changing Participating Factors of Generators", International Journal of Modern Engineering Research, Vol. 3, No. 4, Aug. 2013.

[10]N. Sambasivarao, J. Amarnath, "Congestion Management Using Facts Devices In Deregulated Power System”, IJRET, Vol. 2, Issue 11, Nov. 2013.

[11]Ms. Namrata Rao, "Congestion Management in Deregulated Power System using Facts Controller", International Journal of Engineering Research and General Science, Vol. 2, No. 6, Nov. 2014.

[12]K. Mawanza, "Congestion Management: Re-dispatch and Application of FACTS", Master of Science Thesis, Department of Energy and Environment, Goteborg, Sweden,2006.

[13]N. Acharya, N. Mithulananathan, "Locating of series FACTS devices for congestion management in deregulated electricity markets", Electric Power System Research, Vol. 77, PP 352-360, May 2007.

[14]N. Acharya, N. Mithulananathan, "A proposal for investment recovery of FACTS devices in deregulated electricity market', Electric Power System Research, Vol. 77, PP 695-703, 2007.

[15]Rony Seto, Naoto Yorino and Mehdi Eghbal, "FACTS Devices Allocation with Control Coordination Considering Congestion Relief and Voltage Stability", IEEE Trans. Power Systems, vol. 26, no. 4, Nov.r 2011.

[16]D. Venugobal, A. Jayalaxmi, "Congestion Management in Deregulated Power System by Optimal Choice and Allocation of FACTS Controllers Using Multi-Objective Genetic Algorithm", International Journal of Soft Computing and Engineering, vol. 4, no. 3, July 2014.

[17]A. Pillay, S. Prabhakar, "Congestion management in power systems - A review”, Elsevier, vol. 70, pp 83-90, 2015.

[18][18] Rony Seto, Naoto Yorino and Mehdi Eghbal, "FACTS Devices Allocation for Congestion Management Considering Voltage Stability by Means of MOPSO”, IEEE T\&D Asia 2009.

[19] K. Balamurugan, R. Muralisachithanandam, "Performance comparison of evolutionary programming and differential evolution approaches for social welfare maximization by placement of multi type FACTS devices in pool electricity market", Electrical power \& Energy Systems, vol. 67, $517-528,2015$.

[20]R. Benabid, M. Boudour, and M. Abido, "Optimal Location and Setting of SVC and TCSC Devices using Non-Dominated Sorting Particle Swarm
Optimization", Elect. Power Syst. Res., 79 (12), PP. 1668-1677, Dec.2009.

[21]S. Gerbex, R. Cherkaoui, and A. Germond, "Optimal Location of MultiType FACTS Devices in Power System by Means of Genetic Algorithm," IEEE Trans. Power Syst., vol. 16, no. 93, pp. 537-544, Aug.2001.

[22] S.Surender Reddy, "Multi-Objective Based Congestion Management Using Generation Rescheduling and Load Shedding", IEEE Trans. On Power Systems, vol. 32, No. 2, March 2017.

[23] F. Schweppe and M. Caraminis, "Spot Pricing of Electricity", 1998.

[24] T. Gedra "On Transmission Congestion and Pricing", IEEE transacton on Power Systems, vol. 14, 1999.

[25] P. Marannino, E. Bompard and G. Gross, "OPF tools for optimal pricing and congestion management in two sided auction market structure", IEEE Porto Power Tech Conference, 2001

[26] M. Esmaili, H. Ali, and R. Moslemi, "Locating series FACTS devices for multi-objective congestion management improving voltage and transient stability", European Journal of Operational Research, vol. 236, pp. 763 - 773, 2014.

[27] M. T. TRAN, "Definition and Implementation of Voltage Stability Indices in PSS", Master of Science Thesis in Electric Power Engineering, Chalmers University Of Technology, Sweden, 2009.

[28] M. Mechell, An Introduction to Genetic Algorithm, 5th edition 1999.

[29] R. Haupt " Practical Genetic Algorithm.", $2^{\text {nd }}$ edition 2004.

[30] Rahmat-Allah Hooshmand, Mohammad Javad, "Congestion management by determining optimal location of series FACTS devices using hybrid bacterial foraging and Nelder-Mead", Journal of Applied Soft Computing , vol. 28, PP 57-68, 2015.

[31] K. Kavitha and R. Neela, "Comparison of BBO, WIPSO \& PSO techniques for the optimal placement of FACTS devices to enhance system security "Recent Advancement and Effectual Researchers in Engineering Science and Technology (RAEREST), vol. 25, PP 824837, 2016.

[32] A. R. Moradi, Y. Alenjad-Beromi and K. Kiani,"Locating of Series FACTS. Devices for Multi-Objective Congestion Management Using Components of Nodal Prices.", Iranian Journal of Electrical and Electronic Engineering, vol. 13, No. 1, March 2017.

[33] R. Zimmermann and D. Gan, "Matpower: a Matlab Power System Simulation Package", User Manual Version 6.0b2, 2014 